\title{
Digestibility at several intestinal sites in pigs
}

\author{
By A. G. Low, National Institute for Research in Dairying, Shinfield, Reading \\ $R G 2$ gAT
}

In recent years the apparent digestibility of nutrients from a variety of diets has been measured at several intestinal sites in growing pigs during studies on the general characteristics of the digestive processes. The results of some of this work were reviewed by Low (1976). The present review will consider the methods currently in use for such measurements in pigs in relation to their possible value for the practical evaluation of feeds. A detailed review of other methods which can be used to study the digestive processes in simple-stomached animals has been made by Laplace (1972).

\section{Serial slaughter}

The oldest and simplest method of studying the progress of digestion within the intestine is serial slaughter which permits simultaneous assessment throughout the organ but at only one point of time. In order to obtain a picture of the time changes in digestion following feeding, or to investigate the digestion of a variety of diets, a large number of animals are required. A serious criticism of this method is the likely occurrence of large scale mucosal cell shedding into the lumen of the intestine following death by electrical stunning (Badawy, Campbell, Cuthbertson \& Fell, 1957; Horszczaruk, 1971a) and this can give misleading information on the digestion of protein, for example. Nevertheless, much important information on the general characteristics of digestion in pigs has been obtained using this method.

\section{Simple and re-entrant cannulation}

The use of permanent cannulas permitting repeated observations of digestion in conscious pigs over periods of several months at one or more intestinal sites has been developed in recent years. Simple 'T-piece' or 'Y-piece' cannulas are used for discontinuous 'spot' sampling of digesta, in conjunction with non-absorbed markers, while re-entrant cannulas divert the entire flow of digesta outside the animal and allow the total flow of nutrients during periods of $24 \mathrm{~h}$ or more to be measured with confidence. The surgical techniques involved in the preparation of animals with simple or re-entrant cannulas are similar: during the administration of general anaesthesia a lateral or ventral incision is made through the body wall, and the desired intestinal site is located. If re-entrant cannulas are to be fitted the intestine is transected and the blind ends of intestine closed with sutures. A small incision is made into the intestine (adjacent to each of the blind ends in the 
case of re-entrant cannulas), the cannula(s) is inserted, and the intestine wall tightened around the barrel with a purse-string suture. The cannula(s) is then exteriorized through a stab wound and re-entrant cannulas are then firmly linked externally. In our experience at Shinfield we have found that perspex 'T-piece' cannulas crack rather easily but cannulas made from polyacetate materials have been exceptionally resistant to damage. Re-entrant cannulas made from PVC were described by Ash (1962); these have the advantage of flexibility and they project very little from the body wall, but are rather easily pulled out of the fistulas unless strengthened internally (Braude, Fulford \& Low, 1976). The detailed surgical methodology for the insertion of cannulas was described by Markowitz, Archibald \& Downie (1954) and the simple cannula preparation was adapted for pigs by Kvasnitskii (1951), Redman, Teague, Henderickx \& King (1964) and Horszczaruk, Zebrowska \& Dobrowolski (1972), among others. The re-entrant cannula has been adapted for pigs by Cunningham, Friend \& Nicholson (1962), Laplace \& Tomassone (1970), Easter \& Tanksley (1973), Holmes, Horney \& Leadbeater (1973) and Horszczaruk \& Zebrowska (1973). An interesting cannula design has been described by Ivan (1974); this combines the intestinal integrity associated with the simple cannula, and the ability to collect, sample and return all of the digesta, associated with the re-entrant cannula.

In our experience at Shinfield pigs with simple cannulas recover their appetite fully 2-3 $d$ after surgery and those with re-entrant cannulas about a week after surgery. Once normal appetite has been regained the pigs grow at similar rates to pigs without cannulas. Pigs with simple cannulas can be used for collections over periods of many months, while those with re-entrant cannulas can be used for at least ten collections each of $24 \mathrm{~h}$ duration; the subsequent longevity of such preparations is very variable, but the commonest reason for ending collections is leakage of digesta from around the cannulas. We have found that it is desirable to arrange the cannulas and their connections so that they project as little as possible from the body wall and to provide cages with smooth sides and with floors giving adequate adhesion but without spaces large enough for cannulas to become caught (Braude et al. 1976). Daily cleaning and application of zinc ointment is important to keep the skin surrounding cannulas in good condition.

\section{Problems associated with studies involving intestinal cannulas}

Among the difficulties associated with simple cannulas is uncertainty about the degree to which 'spot' samples are representative of the flow of digesta past the cannula. (It may be noted that studies with re-entrant cannulas in the terminal ileum have shown that the composition of the digesta at this site during $24 \mathrm{~h}$ periods is much more uniform than at sites in the proximal small intestine, so more representative sampling of ileal than of duodenal or jejunal digesta should be possible.) Other problems with simple cannulas concern how frequently samples should be taken, and whether sedimentation of the digesta occurs in or near the barrel of the cannula during sampling, giving digesta samples which are not representative of the material flowing within the intestinal lumen. In each case 
these problems are mitigated to some extent by the use of markers. Although a wide range of markers are available for studies of the digestive system (Kotb \& Luckey, 1972), chromic oxide and polyethylene glycol have been used in most recent studies in the pig to mark the solid and liquid phases of the digesta, respectively. In studies of digestion in the duodenum and ileum of pigs Horszczaruk $(1971 b)$ obtained similar mean apparent digestibility values with simple and re-entrant cannulas although the individual measurements were more variable with simple cannulas. In view of these findings and in view of the simplicity of preparation of simple cannulas, and the long survival times of pigs with such cannulas, as well as the possibility of collecting samples from a large number of pigs simultaneously, a systematic study of the variation associated with simple cannulas, and of the most appropriate markers to use is merited.

The disadvantages of the re-entrant cannula method are (a) that the surgical procedures involved are relatively complex and about $25 \%$ of preparations are not suitable for sampling, (b) that continuous collection, sampling, and return of digesta involves either a higher labour input for a given number of animals than with simple cannulas or the use of complex automated equipment not yet available (even when this is developed it will probably not be possible to leave pigs alone for more than about 30 min during digesta collections), and (c) that the severed nerve supply of the intestine adjacent to the cannulas can result in disturbed and reduced intestinal muscle activity leading to blockage problems, particularly with ileal reentrant cannulas (Laplace \& Borgida, I976). However, at Shinfield we have found that if diets are ground to pass through a I $\mathrm{mm}$ mesh, then Ash re-entrant cannulas in the terminal ileum very rarely become blocked (Braude et al. 1976).

In view of the fact that the stomach of the pig empties virtually completely every $24 \mathrm{~h}$, most workers using pigs with re-entrant cannulas have considered that markers are not necessary if collections last for $24 \mathrm{~h}$ or longer; it has been assumed that variations in digesta flow from one $24 \mathrm{~h}$ collection period to another are a normal feature of digestion; this variation would be disguised if the results were corrected for $100 \%$ marker recovery. The known unreliability of markers has also discouraged their use in conjunction with re-entrant cannulas. On the other hand, if such variations in digesta flow are considered to be due to disturbances arising from the presence of cannulas and collection procedures, then flow correction for marker recovery can be justified. More information on whether the pattern of movement of digesta is altered after inserting re-entrant cannulas in pigs is required.

\section{Sample collection}

A method for collecting samples from simple cannulas was described by Horszczaruk et al. (1972). In most studies with re-entrant cannulas in pigs digesta has been collected by free drainage of $200-300 \mathrm{~g}$ into a beaker; after sampling it has been poured slowly back into the pig (Horszczaruk \& Zebrowska, 1973). Partial automation of this procedure was described by Braude $e$ t al. (1976), and a novel method of full automation is now being developed at Shinfield. 


\section{Digestion and endogenous secretions}

Studies using the methods described above have shown widely different patterns of digestion and absorption of a variety of proteins and carbohydrates at several intestinal sites, especially in the jejunum. It seems likely that the factors responsible, namely the physical and chemical structure of the diet and the nature and adaptability of the digestive processes are important determinants of subsequent nutrient utilization by the pig. Identification of these factors is the subject of current research in various centres. At the terminal ileum the differences between diets for the apparent digestibility of individual amino acids for example, are much less than in the jejunum. However, in studies at any intestinal site the measured amount of a digesta constituent includes both the dietary component and additions in the form of secretions from the salivary glands, stomach, liver, pancreas and intestinal wall. The factors influencing these endogenous secretions are currently being studied to a limited extent; further investigation is needed before the dietary and endogenous components of the digesta can be accurately distinguished. It is possible that such studies will ultimately provide estimates of endogenous secretion which are more reliable than those obtained in investigations with specific nutrient-free diets, for the measurement of the true digestibility of feeds.

\section{Feed evaluation from digestibility measurements in the terminal ileum}

The recognition that the large intestinal microflora of monogastric animals ferments undigested dietary residues to yield products of no nutritional benefit to the animal has led to the view taken by Payne, Combs, Kifer \& Snyder (1968) and Varnish \& Carpenter (1975) that the digestibility of proteins in rats and chicks respectively may best be measured in ileal digesta. Michel (1966) observed extensive deamination of amino acids in in vitro studies of large intestinal digesta from pigs. The lack of nutritional importance of the large intestine of pigs for protein digestion and absorption was demonstrated in vivo by Zebrowska (1973) who showed that either intact casein or enzymically hydrolysed casein infused into the terminal ileum of pigs fed on a nitrogen-free diet was partially digested and absorbed; the absorbed material was rapidly and completely excreted in the urine. When practical diets were fed to growing pigs, Holmes, Bayley, Leadbeater \& Horney (1974), Braude, Low, Partridge \& Sambrook (1975) and Low (1975) noted that over-all apparent digestibility values of various nutrients were of the order of 0.05 higher than values obtained at the terminal ileum. However, there was also evidence of net accumulation of some amino acids during transit of the large intestine. In a recent study Livingstone, Atkinson, Baird \& Crofts (1977) noted very large differences between over-all apparent digestibility measurements and corresponding values for ileal digesta for diets containing potatoes processed in various ways: the ileal apparent digestibility value in this work was probably of much greater nutritional relevance than the corresponding over-all value. In cases where a novel feed is being evaluated or where processing of a feed is suspected to 
have changed its nutritive value, ileal apparent digestibility values are likely to be of particular utility. A detailed investigation of the nature of the undigested residue of protein or peptide in ileal digesta may be merited where utilization of a feed is poor. However, it is important to note that measurements of the absorbability of minerals by analysis of ileal digesta are likely to lead to erroneous conclusions about net mineral absorption in some cases (Partridge, 1975).

A tentative estimate of the approximate number of pigs required to show significant differences $(P<0.05)$ between treatments in apparent digestibility of 0.05 of organic matter, $\mathrm{N}$, lysine and threonine has been made, using results obtained at Shinfield. In these studies pigs were fed on barley-weatings-fishmeal diets or purified diets with casein or groundnut as the only protein sources. Such a difference would be shown by not less than ten pigs with $96 \mathrm{~h}$ collections from ileal re-entrant cannulas, and by not less than five pigs with $120 \mathrm{~h}$ faeces collections; these numbers are required to have an $80 \%$ chance of obtaining a significant result. Similar variability in both ileal and over-all apparent digestibility measurements has been found by other workers.

A note of caution about the estimation of the nutritive value of feeds from digestibility measurements in the terminal ileum is that microbial fermentation occurs in the stomach and small intestine of the pig (Cranwell, 1968; Clemens, Stevens \& Southworth, 1975) resulting, for example, in notable fibre digestion anterior to the terminal ileum (Braude et al. 1975), and doubtless of other nutrients also.

In spite of the considerable technical problems involved in the surgery, housing and sample collection from pigs with cannulas, it seems clear, on present evidence, that the most useful apparent digestibility values for protein are likely to be obtained from ileal digesta measurements. The same cannot yet be said for carbohydrates because of inadequate experimental results. It will be of considerable interest in the future to see whether clearer relationships will be found between digestibility measurements in the ileal digesta of pigs and subsequent nutrient retention than are found currently when over-all digestibility is compared with retention; circumstantial evidence already suggests that this will be the case.

\section{REFERENCES}

Ash, R. W. (1962). Anim. Prod. 4, 309.

Badawy, A. M., Campbell, R. M., Cuthbertson, D. P. \& Fell, B. F. (1957). Nature, Lond. 180, $75^{6}$. Braude, R., Fulford, R. J. \& Low, A. G. (1976). Br. F. Nutr. 36, 497.

Braude, R., Low, A. G., Partridge, I. G. \& Sambrook, I. E. (1975). Proc. Nutr. Soc. 34, 46A. Clemens, E. T., Stevens, C. E. \& Southworth, M. (1975). J. Nutr. 105, 759.

Cranwell, P. D. (1968). Nutr. Abstr. Rev. 38, 26.

Cunningham, H. M., Friend, D. W. \& Nicholson, J. W. G. (1962). Can. J. Anim. Sci. 42, 112. Easter, R. A. \& Tanksley, T. D. (1973). F. Anim. Sci. 36, rog9.

Holmes, J. H. G., Homey, F. D. \& Leadbeater, P. A. (1973). Am. f. vet. Res. 34, 1365.

Holmes, J. H. G., Bayley, H. S., Leadbeater, P. A. \& Horney, F. D. (1974). Br. Y. Nutr. 32, 479.

Horszczaruk, F. (1971a). Biul. Inst. Genet. Hodow. Zwierr. pol. Akad. Nauk. no. 21 , p. I 17.

Horszczaruk, F. (1971b). Biul. Inst. Genet. Hodow. Zwierz. pol. Akad. Nauk. no. 21, p. 137.

Horszczaruk, F. \& Zebrowska, T. (1973). Roczn. Nauk roln. Ser. B 95, (1), 157.

Horszczaruk, F., Zebrowska, T. \& Dobrowolski, W. (1972). Roczn. Nauk roln. Ser. B 94, (3), 99. 
Ivan, M. (1974). Aust. vet. f. 50, 547.

Kotb, A. R. \& Luckey, T. D. (1972). Nutr. Abstr. Rev. 42, 813.

Krasnitskii, A. V. (I951). Voprosy Fixiologii Pishchevarenija u Svinei. Moscow: Sel'Khozgiz. (Translated by D. E. Kidder).

Laplace, J.-P. (1972). Annls Zootech. $21,83$.

Laplace, J.-P. \& Borgida, L. P. (1976). Annls Zootech. 25, 36r.

Laplace, J.-P. \& Tomassone, R. (1970). Annls Zootech. 19, 303.

Livingstone, R. M., Atkinson, T., Baird, B. \& Crofts, R. M. J. (1977). Proc. Nutr. Soc. 36, 58A.

Low, A. G. (1975). Proc. Nutr. Soc. 34, 94A.

Low, A. G. (1976). Proc. Nutr. Soc. 35, 57.

Markowitz, J., Archibald, J. \& Downie, H. G. (1954). Experimental Surgery, 3rd ed. London: Balliere, Tindall and Cox.

Michel, M. C. (1966). Annls Biol. anim. Biachim. Biophys. 6, 33.

Partridge, I. G. (1975). Proc. Nutr. Soc. 34, 47A.

Payne, W. L., Combs, G. F., Kifer, R. R. \& Snyder, D. G. (1968). Fedn Proc. Fedn Am. Socs exp. Biol. 27, II 99.

Redman, D. R., Teague, H. S., Henderickx, H. K. \& King, N. B. (1964). F. Anim. Sci. 23, 1032. Varnish, S. A. \& Carpenter, K. J. (I975). Br. J. Nutr. 34, 339.

Zebrowska, T. (1973). Roczn. Nauk roln. Ser. B 95, (3), 85. 